\title{
La culture populaire visuelle : un espace à explorer pour les études critiques de sécurité
}

Visual Popular Culture: A Terrain to be explored for Critical Security Studies

\section{Alex MacLeod}

\section{(2) OpenEdition}

12 Journals

\section{Édition électronique}

URL : http://journals.openedition.org/conflits/19263

DOI : $10.4000 /$ conflits. 19263

ISSN : $1777-5345$

Éditeur :

CCLS - Centre d'études sur les conflits lilberté et sécurité, L'Harmattan

\section{Édition imprimée}

Date de publication : 8 août 2016

Pagination : 17-32

ISBN : 978-2-343-10075-3

ISSN : 1157-996X

Référence électronique

Alex MacLeod, «La culture populaire visuelle: un espace à explorer pour les études critiques de sécurité », Cultures \& Conflits [En ligne], 102 | été 2016, mis en ligne le 08 août 2018, consulté le 30 mars 2021. URL : http://journals.openedition.org/conflits/19263 ; DOI : https://doi.org/10.4000/ conflits. 19263 


\title{
La culture populaire visuelle : un espace à explorer pour les études critiques de sécurité
}

\begin{abstract}
Alex MACLEOD
Alex Macleod est professeur de Relations internationales à l'Université du Québec à Montréal. Ses publications les plus récentes sont "The contemporary fictional police detective as critical security analyst: Insecurity and immigration in the novels of Henning Mankell and Andrea Camilleri ", Security Dialogue, vol. 46, $n^{\circ} 6$, décembre 2014, pp. 515-529 et Movies, Myth, and the National Security State, Boulder, Lynne Rienner Publishers, 2016, rédigé en collaboration avec Dan O'Meara, Frédérick Gagnon et David Grondin.
\end{abstract}

ela fait déjà plus de quinze ans que la culture populaire s'est établie
comme un domaine légitime de recherche et d'enseignement en relations
internationales (RI), du moins dans le monde anglophone ${ }^{1}$. Si les partisans des
approches théoriques les plus classiques en RI (réalisme et libéralisme) ten-
dent à considérer la culture populaire avant tout comme une source secon-
daire, un moyen de représenter les enjeux de la politique internationale à des
fins pédagogiques ${ }^{2}$, pour les théoriciens critiques elle « contient les sites, pra-

1. Voir, entre autres, Weldes J., "Going Cultural: Star Trek, State Action, and Popular Culture ", Millennium, vol. 28, n 1, 1999, pp. 117-134 ; Weber C., International Relations Theory: A Critical Introduction, Londres, Routledge, 2001 (4e édition publiée en 2013); Weldes J. (dir.), To Seek Out New Worlds: Exploring Links between Science Fiction and World Politics, New York, Palgrave Macmillan, 2003 ; Neumann I., Nixon D., Harry Potter and International Relations, Lanham, Rowman and Littlefield, 2006 ; Drezner D., Theories of International Politics and Zombies, Princeton, Princeton University, 2011 ; Carter S., Dodds K., International Politics and Film: Space, Vision, Power, Londres et New York, Columbia University Press, 2014 ; Caso F., Hamilton C. (dir.), Popular Culture and World Politics: Theories, Methods, Pedagogies, Bristol, E-International Relations, 2015, http://www.e-ir.info/2015/04/22/edited-collection-popular-culture-and-world-politics/. Il faudrait mentionner aussi la série d'ouvrages consacrée aux rapports entre la culture populaire et la politique globale publiée par la maison d'édition britannique Routledge.

2. Voir, par exemple, Gregg R. W., International Relations on Film, Boulder, Lynne Rienner, 1998 et Walt S. M., "Foreign policy film festival ", Foreign Policy, 27 avril 2009, http://foreignpolicy.com/2009/04/27/foreign-policy-film-festival/ (consulté le 28 février 2016). 
tiques et cadres principaux à travers lesquels les gens comprennent le monde ${ }^{3} \gg$. Elle constitue donc un terrain tout désigné pour les études critiques de sécurité, mais un terrain qui demeure encore relativement peu exploré ${ }^{4}$.

Lorsque l'on s'interroge sur ce que la culture populaire peut apporter aux études de sécurité, il devient rapidement évident que l'on se trouve devant un champ immense qui implique des choix. Un premier choix concerne la ou les formes de culture populaire à privilégier - romans, musique, cinéma, télévision, etc. Un deuxième choix porte sur les questions ou les sujets que l'on souhaite explorer en matière de sécurité. Enfin, il faut indiquer la méthodologie utilisée pour les traiter.

Dans cet article, nous avons choisi de nous concentrer sur ce que la culture populaire visuelle, en particulier les films et les séries télévisées ${ }^{5}$, peut apporter aux études critiques de sécurité, car, comme le dit si bien Cynthia Weber, le langage visuel est devenu le «langage de la culture populaire contemporaine ${ }^{6}$ ». C'est évidemment un territoire très vaste que nous n'avons pas voulu trop limiter. Nous avons donc décidé d'explorer un domaine auquel la culture populaire visuelle, par sa nature même, apporte l'une de ses plus grandes contributions aux études critiques de sécurité : le domaine de la « problématique sécuritaire » d'une société particulière à l'époque où le film ou la série télévisée ont été produits. Cette problématique comprend, entre autres, les débats sur les enjeux de la sécurité, le processus de sécuritisation, les activités des organismes de renseignement et de sécurité, les pratiques sécuritaires et l'imaginaire sécuritaire. Nous commencerons par une réflexion sur les rapports entre culture populaire visuelle et sécurité. Nous poursuivrons en pro-

3. Rowley C., An intertextual analysis of Vietnam war films and US presidential speeches, Thèse de doctorat, Université de Bristol, 2010. L'auteur est responsable des citations traduites de l'anglais, y compris celles du dialogue des films et des séries télévisées.

4. Pour des recherches critiques récentes sur les rapports entre la culture populaire et la sécurité, voir Ramírez Berg C., Latino Images in Film: Stereotypes, Subversion, Resistance, Austin, University of Texas Press, 2002 ; Weber C., Imagining America at War: Morality, politics, and film, Oxford, Routledge, 2005 ; Rowley C., Weldes J., « The evolution of international security studies and the everyday: Suggestions from the Buffyverse ", Security Dialogue, vol. 43, $\mathrm{n}^{\circ}$ 6, 2012, p. 526 ; Shepherd L. J., Gender, Violence and Popular Culture: Telling Stories, Londres, Routledge, 2013 ; Carter S., Dodds K., op. cit. ; Macleod, A., « The contemporary police detective as critical security analyst: Insecurity and immigration in the novels of Henning Mankell and Andrea Camilleri », Security Dialogue, vol. 46, n 6, 2014, pp. 515-529; O'Meara D., Macleod A., Gagnon F., Grondin D., Movies, Myth and the National Security State, Boulder et Londres, Lynne Rienner Publishers, 2016.

5. Nous avons volontairement laissé de côté une autre source de culture populaire visuelle importante pour les études de sécurité, les jeux vidéo, car leur nature interactive exige un mode d'analyse différent de celui qui est proposé dans cet article. Pour la contribution de ceux-ci aux études de sécurité, voir, entre autres, Power M., « Digitilized virtuosity: Video war games and post-9/11 cyberterrorism ", Security Dialogue, vol. 38, n 2, 2007, pp. 271-288 et Robinson N., « Have You Won the War on Terror? Military Videogames and the State of American Exceptionalism ", Millennium, vol. 43, n 2, 2015, pp. 450-470.

6. Weber C., «Popular Visual Language as Global Communication: The Remediation of United Airlines Flight 93 », Review of International Studies, vol. 34, numéro spécial, 2008, p. 138. 
posant un mode d'analyse des films et des séries télévisées, qui permet de mettre en exergue ce que ces derniers peuvent nous dire sur la problématique sécuritaire de la société en question. Nous terminerons avec deux études de cas, qui illustrent l'usage de ce mode d'analyse.

\section{Culture populaire visuelle et sécurité}

Si les séries télévisées et les films contemporains semblent refléter une préoccupation grandissante pour la sécurité dans un climat de peur instauré par les événements du 11 septembre 2001 et leurs suites, nous devons constater que la sécurité constitue en fait un thème récurrent de la culture populaire visuelle depuis déjà très longtemps. La notion de sécurité ne se limite pas aux questions relatives à la sécurité nationale et internationale. Elle se situe aussi à un autre niveau, où le cinéma et les séries télévisées sont particulièrement bien placés pour faire une contribution aux études de sécurité, celui où la sécurité et l'insécurité font partie des préoccupations de la vie de tous les jours, que Christina Rowley et Jutta Weldes appellent la « sécurité quotidienne », et qui nous rappelle que «tout le monde, et pas seulement les universitaires et les élites politiques, font de la sécurité 7 ».

La culture populaire visuelle, surtout à cette époque de production rapide de films et de séries télévisées, s’avère un instrument particulièrement puissant pour révéler une autre composante fondamentale de la problématique sécuritaire : la sécurité imaginaire. Emprunté à l'idée de l'« imaginaire social » de Cornelius Castoriadis, ce concept englobe toute la «structure de significations et de relations sociales bien établies à partir desquelles on crée des représentations du monde des relations internationales ${ }^{8}$ ", c'est-à-dire les perceptions des menaces, externes et internes, les perceptions de l'ennemi et les fantasmes quant aux sources d'insécurité et d'anxiété qui imprègnent la société.

Dans leur essai sur les rapports entre la culture populaire et les relations internationales, Iver Neumann et Daniel Nexon proposent deux idées particulièrement pertinentes pour les études de sécurité 9 . La première considère la culture populaire comme source de données sur les normes sociales et politiques, les croyances collectives et les identités qui prévalent dans la société où

7. Rowley C., Weldes J., «The evolution of international security studies and the everyday: Suggestions from the Buffyverse ", art. cité, p. 526.

8. Weldes J., Constructing National Interests: The United States and the Cuban Missile Crisis, Minneapolis et Londres, University of Minnessota Press, p. 10. Voir aussi Muppidi H., «Postcoloniality and the Production of International Insecurity: The Persistent Puzzle of U.S.-Indian Relations », in Weldes J., Laffey M., Gusterson H., Duvall R. (dir.), Cultures of Insecurity: States, Communities, and the Production of Danger, Minneapolis et Londres, University of Minnessota Press, 1999, pp. 123-126. Sur la notion d'imaginaire social, voir Castoriadis C., L'Institution imaginaire de la société, Paris, Seuil, 1999.

9. Neumann I. B., Nexon D., "Introduction: Harry Potter and International Relations », in Nexon D., et Neumann I. B. (dir.), op. cit., pp. 1-23 (nous traduisons) 
le produit culturel en question est situé. Ce sont des données cruciales pour comprendre comment se constitue l'imaginaire sécuritaire.

Neumann et Nexon pointent aussi l'" effet naturalisant » de la culture populaire, qui induit qu'une «manière particulière de regarder le monde semble faire partie de l'ordre naturel, présente les choses "simplement comme elles sont”, et semble ainsi difficilement contestable 10 ». La culture populaire peut participer d'une certaine normalisation des moyens d'assurer la sécurité qui auraient été soumis autrefois à un débat de société. On pense, par exemple, à la banalisation de l'usage de la torture au nom de la sécurité nationale, dans des programmes télévisés comme 24 heures chrono ( 24 Hours) ${ }^{11}$, ou au recours à la vidéosurveillance pour faire avancer une enquête, devenu déjà un trope indispensable dans la quasi-totalité des films et séries télévisées policiers contemporains. L'exploitation de la technologie du téléphone dit intelligent que ce soit pour prendre des photos, s'informer sur les appels et les messages reçus par un suspect ou pour suivre les traces de ce dernier - est en train de suivre le même chemin de naturalisation que la vidéosurveillance.

\section{Étudier la sécurité à travers la culture populaire visuelle}

Le point de départ le plus simple et le plus efficace pour initier des recherches sur la sécurité à travers la culture populaire visuelle est, sans conteste, celui qui considère les films et les séries télévisées comme des textes ou des documents auxquels nos lectures peuvent accorder un sens. Mais il faut pouvoir comparer et évaluer la plausibilité des lectures proposées, ce qui nécessite l'adoption d'un cadre d'analyse commun qui permette de mettre en exergue ce que les films et les séries télévisées étudiés peuvent nous apprendre sur la problématique sécuritaire de la société qui les a produits. Le cadre que nous proposons ici procède d'une triple démarche qui consiste à contextualiser, intertextualiser et déconstruire/reconstruire.

Parfois, un metteur en scène, un scénariste ou même un acteur, cherchera à imprimer une ouvre de sa marque idéologique. Et, dans des cas de plus en plus rares, certains réalisateurs parviennent à contrôler toutes les étapes de leur création. Ce fut le cas d'Alfred Hitchcock, qui n’hésitait pas à changer de scénariste, ou simplement à modifier le scénario, parfois à l'insu de son auteur, pour avoir exactement le résultat qu'il voulait ${ }^{12}$. Toutefois, la réalisation d'un

10. Ibid., p. 19.

11. Voir, par exemple, Green A., « Normalizing Torture on '24' », The New York Times, le 22 mai 2005, http://www.nytimes.com/2005/05/22/arts/television/normalizing-torture-on24.html (consulté le 23 février 2016), et Vilmer J-B. J., 24 heures chrono. Le choix du mal, Paris, PUF, 2012, qui propose une analyse plus nuancée de la vision de la torture présentée dans cette série.

12. Par exemple, le scénariste du film Les oiseaux (The Birds, 1963), Evan Hunter, découvrit lors de la première que Hitchcock avait changé la fin du film. Voir Hunter E., "Me and Hitch ", Sight and Sound, vol. 7 (nouvelle série), n 6, 1997, pp. 24-37. 
film ou d'une série télévisée est normalement le résultat d'un travail d'équipe, dont les membres ne partagent pas nécessairement les mêmes positions politiques et, par conséquent, ne peuvent pas contrôler le sens donné à leur œuvre une fois qu'elle est sortie.

\section{Contextualiser}

Traiter un film ou une série télévisée comme un texte indépendant des intentions avouées ou soupçonnées de ses créateurs ne signifie pas que l’on puisse analyser le lien entre culture populaire et sécurité hors contexte, du moins pas dans la perspective proposée ici. Pour apprécier un tant soit peu ce qu'un produit de culture populaire peut nous dire sur la problématique sécuritaire d'une société particulière à une époque donnée, il faut le situer dans le temps et l'espace où il a été créé. Autrement dit, il faut l'appréhender dans le contexte socio-politique qui prévalait au moment de sa réalisation, quand bien même ses créateurs se seraient efforcés de le situer « hors du temps » (en raison de la censure politique par exemple), sinon il perd tout son sens pour les études de sécurité. Prenons l'exemple du film Le corbeau (1943), tourné dans la France de Vichy. L'action se déroule dans un village «quelque part en France », à une époque non précisée, mais manifestement contemporaine. Il y est question d'une série de lettres anonymes et malveillantes qui divisent profondément la population du village, mais sans qu'aucune allusion ne soit faite à la guerre, à l'Occupation ou à la Résistance. Ce film a été très critiqué à la fois par la Résistance et par les partisans du régime de Vichy au moment de sa sortie et a fait l'objet d'une polémique assez violente dans l'après-guerre. Pourtant, on peut le lire comme une dénonciation de la pratique des lettres anonymes accusant des citoyens de prétendues activités de résistance, bien souvent écrites pour des raisons de vengeance personnelle. Dans cette perspective, on peut ainsi considérer qu'il véhicule « des valeurs humanistes opposées à celles des occupants allemands et leurs collaborateurs de Vichy 13 ». Selon cette grille de lecture, Le corbeau devient dès lors un document précieux pour toute recherche sur la résistance politique à travers la culture populaire dans les régimes autoritaires en général et dans la France occupée en particulier.

\section{Intertextualiser}

Quand on entreprend l'analyse d'un film ou d'une série télévisée, on identifie rapidement des points de repère - une trame, une scène, une situation, un geste, une phrase ou un trope - nous permettant d'établir des liens avec d'autres artefacts culturels. Ces liens sont souvent directs ou évidents. Par exem-

13. Gans E., "Clouzot's Cruel Crow ", p.o.v. A Danish Journal of Film Studies, n 20, 2005, p. 52, http://pov.imv.au.dk/Issue_20/POV_20cnt.html (consulté le 5 mars 2016). Voir aussi Williams T., "Le corbeau ", Senses of Cinema, $\mathrm{n}^{\circ}$ 61, novembre 2011, http://sensesofcinema.com/2011/cteq/le-corbeau (consulté le 5 mars 2016). 
ple, il peut s'agir de produits d'un même genre ou sous-genre (western, science-fiction, thriller, musical, etc.), d'une version visuelle d'un livre, ou de films d'un même réalisateur. Mais, au cours de la lecture d'un film, on peut découvrir aussi des rapports indirects ou insoupçonnés avec d'autres films. Ainsi, un lien peut être établi entre des films aussi différents que le film noir En quatrième vitesse (Kiss Me Deadly, 1955) et Le lauréat (The Graduate, 1967), que l'on peut appréhender comme l'histoire du désarroi d'une certaine jeunesse si on les analyse à travers le prisme du consensus face à la guerre froide, composante fondamentale de la conception américaine de la sécurité nationale ${ }^{14}$. Ce travail d'analyse intertextuelle devient indispensable pour toute étude de la problématique sécuritaire dans la culture populaire visuelle, car il met en exergue les similitudes et les différences qui existent à l'intérieur d'une même société, entre des sociétés et entre des époques. Habituellement, l'intertextualisation se fait de façon diachronique - en établissant des références ou des comparaisons avec des artefacts de culture populaire en amont ou en aval de leur réalisation - ou synchronique - dans le cas de références à des œuvres produites à une même époque.

Un des cas les plus manifestes d'intertextualité est sans doute celui du remake, pratique courante depuis longtemps dans le cinéma ${ }^{15}$ et de plus en plus répandue dans le domaine des séries télévisées. La première saison de la série policière suédo-danoise Bron/Broen (Le pont, 2011) nous offre un exemple récent de ce phénomène. Cette série relate l'histoire d'une enquête sur une série de meurtres commis de chaque côté de la frontière entre le Danemark et la Suède et débute avec la découverte d'un cadavre placé à part égale sur la ligne frontalière, au beau milieu du pont reliant Copenhague à Malmö. Cette découverte déclenche une opération conjointe menée par des policiers danois et suédois, qui circulent constamment entre les deux villes. Cette série a été suivie d'une coproduction franco-britannique, Tunnel (2013), dans laquelle le cadavre à l'origine de l'enquête était retrouvé dans l'Eurotunnel entre Folkestone et Calais, puis d'une version américaine, The Bridge (2013), où l'action se déroulait entre El Paso aux États-Unis et Ciudad Juarez au Mexique. Les trois versions racontent exactement la même histoire, avec les mêmes personnages, mais nous disent des choses très intéressantes sur la problématique sécuritaire des six pays concernés, notamment sur les perceptions de la frontière et l'imaginaire sécuritaire.

Si Bron/Broen et les séries qui s'en sont inspirées nous démontrent l'intérêt de l'intertextualisation synchronique, les westerns de John Ford, surtout ceux tournés au cours de la guerre froide, témoignent quant à eux des apports de l'intertextualisation diachronique. Ainsi, pour apprécier ce que le film $\mathrm{La}$

14. Sur les liens entre ces deux films et le consensus face à la guerre froide, voir O’Meara D. et al., op. cit., pp. 72-82 et 112-115.

15. Sur le phénomène du remake au cinéma, voir Forrest J., Koos L. R., Dead Ringers: The Remake in Theory and Practice, Albany, State University of New York Press, 2001. 
prisonnière $d u$ désert (The Searchers, 1956) peut nous dire sur l'évolution du concept américain du National Security State ${ }^{16}$, il faut l'analyser au regard, d'une part, des westerns que Ford a tournés auparavant - notamment sa célèbre trilogie de la cavalerie : Le massacre à Fort Apache (Fort Apache, 1948), La charge héroïque (She Wore a Yellow Ribbon, 1949) et Rio Grande (1950) - et, d'autre part, de ceux qui ont suivis - en particulier Les deux cavaliers (Two Rode Together, 1960), et Les Cheyennes (Cheyenne Autumn, 1964).

L'analyse intertextuelle diachronique de ces westerns nous permet d'explorer l'évolution des rapports entre des éléments fondamentaux de l'imaginaire sécuritaire des États-Unis au cours de la guerre froide : la différence, l'identité et la nature de la menace. La prisonnière $d u$ désert raconte l'histoire d'un homme qui cherche pendant plusieurs années sa nièce, enlevée par un groupe de Comanches. Quand il la retrouve enfin, il constate qu'elle est devenue Comanche et a complètement oublié ses origines culturelles et raciales, situation qu'il trouve insupportable. Le film offre une réflexion sur la différence et les lignes de fracture à l'intérieur de la société américaine. Il marque aussi un tournant par rapport aux trois films de la trilogie de la cavalerie par sa prise de position à l'égard de la menace que représente l'Autre : le "peaurouge ». Située aux confins de la frontière de la «conquête de l'Ouest », la caserne où vivent les militaires et leurs familles dans ces trois films est dépeinte comme le portrait bien connu d'une communauté où règnent l'ordre et la sécurité internes au milieu d'un monde externe caractérisé par le désordre et le danger permanents.

Ces trois films posent à un premier niveau la question de la possibilité de vivre en paix entre groupes de cultures distinctes sur un même territoire et, à un deuxième niveau, la problématique de la coexistence entre des sociétés porteuses d'idéologies différentes sur le plan international. Le massacre à Fort Apache, tourné en 1947, au début de la guerre froide, semble indiquer que l'accommodement est encore possible, pourvu qu'il existe un climat de confiance et de bonne volonté réciproque. La duplicité et l'obstination aveugle du commandant de la caserne mettent fin à ces espoirs. Dans La charge hérö̈que et Rio Grande, nous assistons non seulement au durcissement des positions des deux côtés, mais aussi à l'affirmation de l'identité américaine, opposée à celle de l'ennemi, les « sauvages ». Les parallèles avec l'évolution de la guerre froide

16. Le concept américain de National Security State, tout comme celui de unAmerican, est intraduisible et se réfère à l'idée que la vie publique est largement régie par l'existence d'une menace permanente planant sur la sécurité nationale, définie non seulement en termes d'intérêts matériels et de menaces externes, mais aussi de menaces sur les valeurs fondamentales, et où l'on accorde la primauté aux institutions, lois, et pratiques censées protéger la sécurité nationale. Pour une analyse plus détaillée de l'évolution de la problématique sécuritaire des États-Unis à travers les westerns de John Ford (et surtout la trilogie de la cavalerie), voir O’Meara D. et al., op. cit., pp. 41-64. Pour La prisonnière du désert, voir Henderson B., «'The Searchers' : An American Dilemma », Film Quarterly, vol. 24, n², 1980-1981, pp. 9-23 et Carter M., Myth of the Western: New Perspectives on Hollywood's Frontier Narrative, Édimbourg, Edinburgh University Press, 2015, pp. 77-113. 
sont évidents. En revanche, les westerns de Ford qui suivent La prisonnière $d u$ désert, réalisés à l'époque du dégel entre les États-Unis et l'Union soviétique, plaident de plus en plus en faveur de la réconciliation entre le peuple américain et l'Autre. Ce faisant, Ford invite ses spectateurs à concevoir la différence et l'identité dans un esprit d'inclusion, qui tranche avec la vision quelque peu « exclusionniste » des deux derniers films de la trilogie de la cavalerie.

\section{Déconstruire/reconstruire}

La déconstruction/reconstruction constitue l'étape la plus difficile dans le processus d'analyse d'un artefact de culture populaire visuel. Cette démarche consiste à déconstruire le film ou le programme télévisé pour aller au-delà de son récit immédiat, puis à le reconstruire du point de vue de ce qu'il dit de la problématique sécuritaire. Ce processus s'impose de lui-même lorsque cette problématique est présentée sous la forme d'une parabole ou d'une métaphore. Mais même dans le cas d'une histoire qui aborde directement des questions de sécurité, la déconstruction/reconstruction est absolument nécessaire pour révéler l'histoire derrière l'histoire. Ainsi, les films de James Bond nous racontent les aventures d'un espion britannique qui tente de raviver la gloire passée d'une ancienne puissance impérialiste en déclin, mais nous fournissent aussi des renseignements intéressants sur la culture nucléaire britannique et sur la persistance des stéréotypes britanniques sur l'identité russe que seule une lecture intertextuelle peut nous révéler ${ }^{17}$.

Il est intéressant de constater que procéder à une telle analyse sur un même film à des époques différentes peut aboutir à des résultats contradictoires. Prenons pour exemple le western Le train sifflera trois fois (High Noon, 1952). À première vue, ce film contient tous les ingrédients d'un western classique, où un homme seul se bat avec courage et succès pour protéger sa ville et ses habitants contre une bande de hors-la-loi. Au fur et à mesure du film, le spectateur réalise rapidement que la trame de l'histoire est beaucoup plus complexe. Le shérif Will Kane (Gary Cooper), qui vient de se marier, se prépare à prendre sa retraite quand il apprend que Frank Miller (Ian MacDonald), qu'il a mis derrière les barreaux cinq ans plus tôt, vient d'être amnistié et arrive par le train de midi, avec une seule idée en tête : se venger de Kane. Celui-ci décide alors qu'il ne peut abandonner les habitants de la ville à la merci de celui qui les avait terrorisés dans le passé. C'est à partir de ce moment-là que le scénario s'écarte de celui du western traditionnel. Malgré des appels à l'aide, les concitoyens de Kane se récusent presque tous, que ce soit par peur, par lâcheté, par hostilité personnelle à son égard, ou parce qu'ils croient que l'arri-

17. Sur ces thèmes, voir Laucht $\mathrm{C}$., «Britannia Rules the Atom: The James Bond Phenomenon and Postwar British Nuclear Culture ", Journal of Popular Culture, vol. 46, n² 2, 2013, pp. 358-377 et Lawless K., "Constructing the 'other': construction of Russian identity in the discourse of James Bond films ", Journal of Multicultural Discourses, vol. 9, n², 2014, pp. 7997. 
vée de Miller ravivera l'économie locale. Abandonné de tous, y compris de sa nouvelle femme Amy (Grace Kelly), une Quakeresse qui refuse toute forme de violence, Kane commence à douter du bien-fondé de sa décision d'affronter son ennemi et, à la différence du héros typique de ce genre de film, pense un instant à tout laisser tomber. Mais il se ressaisit et décide d'aller jusqu'au bout de son idée première. Il élimine Miller et sa bande, avec l'aide de dernière minute d'Amy, qui met de côté ses convictions religieuses, ramasse un révolver à terre et tue un homme sur le point de tirer sur son mari. Dans la dernière scène, Kane, désabusé, jette son étoile de shérif à terre et quitte la ville.

Le scénariste du Train sifflera trois fois, Carl Foreman, connu pour ses sympathies de gauche, aurait voulu que ce film soit vu comme une allégorie de la lutte contre le maccarthysme, position que ne partageait pas son réalisateur, Fred Zinnemann ${ }^{18}$. C'est une lecture largement répandue, mais contestée. Selon le commentateur et critique de cinéma conservateur Kyle Smith, aujourd'hui, ce film « donne l'impression d'une œuvre conservatrice ». Selon lui, il peut être appréhendé comme un « avertissement contre les dangers de toute attitude indulgente à l'égard du crime, national ou international » et une allégorie « des États-Unis, gendarme du monde du dernier recours 19 ». Enfin, selon Peter Biskind, si ce film se situe bien à gauche dans le contexte de 1952, il rejoint des films de droite dans ses attaques contre le consensus centriste de l'époque. Ainsi, " une fois dépouillé de son contexte historique, on ne peut le distinguer de L'inspecteur Harry 20 ».

\section{Culture populaire et études critiques de sécurité : deux études de cas}

Dans cette dernière section, nous nous penchons sur deux produits de culture populaire visuelle bien différents mais tous deux issus de périodes de grande tension sur le plan sécuritaire, afin d'illustrer la manière dont le mode

18. Pour une histoire détaillée des circonstances entourant le tournage du film et son impact politique, voir Byman J., Showdown at High Noon: Witch-Hunts, Critics, and the End of the Western, Lanham, Scarecrow Press, 2004. Ayant refusé de donner des noms d'anciens membres du parti communiste des États-Unis à la Commission des activités anti-américaines de la Chambre des représentants (HUAC) en 1951, Foreman fut inscrit sur la liste noire des producteurs de Hollywood, et obligé de quitter les États-Unis. Zinnemann aurait préféré que son film soit vu uniquement comme un simple western.

19. Smith K., «The Real Political Message of High Noon », PJ Media, le 10 juin 2008, https//:pjmedia.com/blo/theOreal-political-message-of-hihg-noon/ (consulté le 16 mars 2016).

20. Biskind P., Seeing Is Believing: How Hollywood Taught Us to Stop Worrying and to Love the Fifties, New York, Pantheon Books, 1983, p. 48. Nous laissons le mot de la fin au professeur de littérature anglaise, Manfred Weidhorn, qui met en garde contre toute lecture trop tranchée de ce film, et conclut : "En fait, Le train sifflera trois fois n'est ni libéral ni conservateur parce que de telles idéologies sont des simplifications de la réalité. Ceux qui mettent ce film dans un camp ou dans l'autre sont simplement en train d'ignorer des détails qui ne cadrent pas avec leurs généralisations suffisantes. » Weidhorn, M., «High Noon: Liberal Classic? Conservative Screed? ", Bright Lights Film Journal, le 31 janvier 2005, http://brightlightsfilm.com/high-noon-liberal-classic-conservativescreed/\#.VTvu35OwKGM (consulté le 25 avril 2015). 
d'analyse présenté ici peut contribuer à l'approfondissement des études critiques de sécurité. Le premier est un film à suspense américain bien connu des années 1950, du célèbre metteur en scène britannique Alfred Hitchcock, Fenêtre sur cour (Rear Window, 1954). Le second est une série policière de la télévision danoise des années 2000, The Killing II (2009), qui a connu un grand succès, non seulement dans les pays scandinaves, mais aussi dans d'autres pays européens.

\section{Fenêtre sur cour : portrait d'une société sous haute surveillance}

Sans conteste l'un des grands classiques du répertoire hitchcockien, Fenêtre sur cour dresse le portrait d'une petite communauté apparemment sans histoires, sur laquelle aucune menace ne semble planer, ni interne ni externe. Son protagoniste principal L. B. (Jeff) Jeffries (Jimmy Stewart), photographe de presse, se remet d'une fracture de la jambe gauche et, pour faire passer le temps, il épie à la jumelle et au téléobjectif de son appareil photo ses voisins de son complexe d'appartements new-yorkais. Il observe ainsi un groupe de personnes vivant seules ou enfermées dans des relations peu affectueuses, et qui s'adressent rarement la parole. Il finit par remarquer que l'un de ses voisins, Lars Thorwald (Raymond Burr), vit avec une femme malade et alitée, qui ne cesse de le narguer. Quand celle-ci disparât subitement, Jeff est persuadé que Thorwald l'a assassinée, a découpé son cadavre et l'a jeté dans l'East River. Incapable d'apporter les preuves qu'exige son ami policier, Tom Doyle (Wendell Corey), Jeff doit compter sur sa fiancée Lisa Fremont (Grace Kelly) pour établir au-delà de tout doute la culpabilité de Thorwald, ce qu'elle parvient à faire sans l'aide de Tom (et donc de la police), qui refuse d'intervenir sur la foi des seuls soupçons de Jeff. Thorwald se rend enfin compte que Jeff l'épie, et le confronte. Jeff se sauve par la fenêtre, et ce faisant, se casse l'autre jambe.

Fenêtre sur cour se déroule sur fond de guerre froide, durant les premières années du National Security State américain. Il a été réalisé en 1953, au moment où l'on percevait les premiers signes, encore timides, de dégel dans la guerre froide, après la mort de Staline et la fin de la guerre de Corée. Sur le plan intérieur, le sénateur Joe McCarthy, avec l'aide de sa sous-commission sénatoriale, menait sa croisade contre la présence de communistes dans l'administration publique. La liste noire des acteurs soupçonnés de sympathies communistes ne cessait de s'allonger et les activités de surveillance du FBI de J. Edgar Hoover battaient leur plein. Cette atmosphère de soupçon, de délation et de méfiance généralisée, que l'historien britannique David Caute appelle la «Grande peur » 21, ne laissait guère de place à la critique des pratiques sécuritaires américaines de l'époque. Or c'est bien ce que propose ce

21. Caute D., The Great Fear: The Anti-Communist Purge Under Truman and Eisenhower, New York, Simon \& Schuster, 1978. 
film réalisé par un metteur en scène peu suspect d'anticonformisme primaire, et encore moins de sympathies de gauche.

Sur le plan de l'intertextualité, Fenêtre sur cour se situe à l'intérieur du corpus général du cinéma à suspense d'Alfred Hitchcock, qui reprend, en les adaptant à l'époque de sa production, certains thèmes de sa perception de la problématique sécuritaire, sur lesquels nous reviendrons un peu plus loin. Ce film appartient aussi à un sous-genre du cinéma et de la télévision qui n’a cessé de fleurir depuis la sortie de ce film, celui de la surveillance ${ }^{22}$, qui comprend notamment les deux versions de 1984 (1956 et 1984), Le Voyeur (Peeping Tom, 1960), Blow-Up (1966), Conversation secrète (The Conversation, 1974), Caché (1996), Ennemi d'État (Enemy of the State, 1998), Minority Report (2002), La vie des autres (Das Leben der Anderen, 2006), Paranoïak (Disturbia, 2007) et Closed Circuit (2013), sans oublier la série télévisée Sur écoute (The Wire, 2002-2008).

Quand on commence à déconstruire/reconstruire ce thriller, on y décèle une parabole à travers laquelle Hitchcock questionne l'éthique et l'utilité de la surveillance ${ }^{23}$. Tous ceux qui entourent Jeff dans son appartement lui font savoir qu'ils désapprouvent ses activités. Dès sa première apparition, son infirmière, Stella (Thelma Ritter), lui fait remarquer qu'ils sont « devenus une race de voyeurs » et Lisa ne cache pas sa désapprobation : "Rester assis, en regardant par la fenêtre pour faire passer le temps, ça va - mais le faire à ta façon avec des jumelles, en émettant des opinions farfelues sur chaque petit mouvement que tu fais - c'est malsain ». Cela n'empêchera ni Lisa ni Stella de se laisser entraîner dans ce jeu d'espionnage, malgré elles. Et son ami Doyle, le policier, lui fait aussi un rappel à l'ordre : «C'est un monde privé que tu es en train de regarder là. Les gens font beaucoup de choses en privé qu'ils ne pourront jamais expliquer en public ».

Jeff finit lui-même par douter de la moralité de cette activité : «Trouvestu qu'il soit éthique de surveiller un homme avec des jumelles, et un téléobjectif, jusqu'à voir les taches de rousseur à l'arrière de son cou, et presque lire son courrier ? Trouves-tu que cela soit éthique, même si tu prouves qu'il n'a commis aucun crime ? »Par ailleurs, si cette surveillance permet de constater qu'un crime a peut-être eu lieu, elle ne peut rien de plus. Jeff somnole au moment où Thorwald quitte son appartement tard dans la nuit, accompagné d'une femme qui n'est manifestement pas son épouse, et rate ainsi un indice

22. Zimmer C., "Surveillance Cinema: Narrative between Technology and Politics », Surveillance and Society, vol. 8, n ${ }^{\circ}$ 4, 2011, pp. 427-440. Pour une réflexion intéressante sur l'éthique de la surveillance à travers le cinéma, voir Light A., Reel Arguments: Film, Philosophy, and Social Criticism, Westview, Boulder, 2003, pp. 21-53.

23. À ce sujet, voir Albrechtslund A., "Surveillance and Ethics in Film: Rear Window and The Conversation ", Journal of Criminal Justice and Popular Culture, vol. 15, n² 2, 2008, pp. 129144. 
crucial de la culpabilité de celui-ci. Il revient donc à Lisa de fournir la preuve nécessaire : l'alliance que l'épouse, supposément partie chez sa mère, a laissée derrière elle.

En dénonçant la pratique de la surveillance, Hitchcock partage également sa perception personnelle de la problématique sécuritaire des États-Unis de l'époque, qui met l'accent sur la sécurité quotidienne. Fenêtre sur cour révèle une société vivant dans l'ombre d'une menace permanente, une société devenue dysfonctionnelle à cause de l'indifférence, de l'égocentrisme et du repli sur soi de ses membres. Hitchcock n'épargne pas non plus l'État et ses représentants, incarnés par le personnage du policier Tom Doyle et présentés comme incompétents. Face aux carences de l'État, il revient à l'individu d'assurer la sécurité, non par l'usage de méthodes violentes, mais par la ruse ou par la simple volonté, et, surtout, par ses propres moyens ${ }^{24}$.

\section{The Killing II : insécurité et politique}

Deuxième saison d'une série policière dont la première a connu un grand succès à la télévision danoise en 2007 25, The Killing II commence par l'assassinat d'une avocate qui a travaillé auprès des forces militaires danoises, notamment en Afghanistan. Ce meurtre est suivi par d'autres, tous liés au premier. Cette série relate simultanément deux histoires distinctes, mais convergentes : une enquête policière et une intrigue politique.

L'enquête policière est menée par l'Inspecteur Sarah Lund (Sofie Gråbøl), femme plutôt rebelle, de caractère difficile, mais tenace, qui suit ses propres intuitions et tient peu compte des ordres de ses supérieurs. Tout semble indiquer un lien entre ces crimes et le terrorisme islamiste. Dans une vidéo diffusée sur internet, la première victime lit une déclaration accusant le gouvernement et le peuple danois de crimes contre l'humanité et contre des Musulmans à travers le monde. La police arrête presque immédiatement le suspect idéal, un sympathisant de l'islamisme radical bien connu, immigré marocain, pro-

24. Sur les idées politiques de Hitchcock, voir Dynia P., " Alfred Hitchcock and the Ghost of Thomas Hobbes », Cinema Journal, vol. 15, n² 2, 1976, pp. 27-41 et Leitch T. M., «It's the Cold War, Stupid: An Obvious History of the Political Hitchcock ", Literature/Film Quarterly, vol. 27, n 1, 1999, pp. 3-15. Pour une analyse de sa perception de l'évolution de la problématique sécuritaire des États-Unis au cours des années 1950 et 1960, voir O’Meara D. et al., op. cit., pp. 87-106. Pour une lecture un peu différente de ce film et de sa critique du National Security State, voir Corber R., In the Name of National Security: Hitchcock, Homophobia, and the Political Construction of Gender in Postwar America, Durham et Londres, Duke University Press, 1999, pp. 83-110.

25. Pour sa première saison, The Killing, diffusé en vingt épisodes le dimanche à une heure de grande écoute (20h), attira entre 1371000 et 2107000 téléspectateurs, et fut de loin le programme le plus regardé à cette heure-là. Présenté entre le 27 septembre et le 29 novembre 2009, ce programme attira un auditoire moyen de plus de 1500 000. Le Danemark compte un peu plus de 5500000 habitants. Voir les chiffres établis par l'agence danoise de mesure d'écoute, TSN Gallup : http://tvm.gallup.dk/tvm/pm/default.htm. Un remake de la première saison de The Killing a été diffusé sur la chaîne américaine AMC en 2011. 
priétaire d'une librairie islamiste, et qui reconnaît avoir diffusé la vidéo sur son site internet. Lund demeure sceptique et conclut assez rapidement qu'il s'agit d'un coup monté de toutes pièces et qu'il faut plutôt chercher les mobiles derrière ces meurtres dans une histoire de massacre de civils en Afghanistan, perpétré par une escouade des forces spéciales danoises, dirigée par un officier du nom de Perk, mais dont on a perdu la trace. Accompagnée de son collègue Ulrick Strange (Mikael Birkkjær), Lund poursuit son enquête en Afghanistan, établit qu'un massacre d'une famille afghane a bel et bien eu lieu, mais n'apprend rien de plus sur l'identité de Perk. Finalement, elle découvre, comme elle commençait à le soupçonner, que le responsable des meurtres au Danemark et du massacre en Afghanistan n'est autre que son collègue Strange, ancien membre des forces armées.

L'intrigue politique et l'enquête policière se déroulent simultanément sans jamais vraiment se rejoindre. Nouvellement nommé ministre de la Justice, Thomas Buch (Nicolas Bro), jeune député naif et idéaliste, se joint au gouvernement minoritaire de centre-droit. Sa première tâche est de négocier un compromis avec les deux partis d'opposition, le Parti populaire danois (PPD) à sa droite et les Progressistes à sa gauche, en vue de faire adopter un projet de loi antiterroriste au Parlement dans la semaine qui suit. Buch ne tarde pas à soupçonner que son prédécesseur, qui s'est suicidé, a tenté d'étouffer le massacre en Afghanistan.

Il commence aussi à mettre en doute le bien-fondé de ce projet et perçoit les dangers que celui-ci représente pour les droits civiques au Danemark. Il est de plus en plus convaincu que le gouvernement cherche à cacher la vérité sur ce qu'il s'est passé en Afghanistan. Il se rend compte, un peu tard, que le Premier ministre l'a choisi uniquement pour négocier l'appui du PPD à un gouvernement menacé de perdre sa majorité au Parlement, et non pas pour améliorer le projet, comme il le pensait. Buch confronte directement le Premier ministre et l'accuse de vouloir cacher la vérité sur le massacre en Afghanistan, mais, se trouvant totalement isolé, il échoue et se voit contraint de démissionner.

The Killing II a été diffusé à la télévision danoise au cours de l'automne 2009, dans un contexte tendu sur le plan sécuritaire. Premièrement, le Danemark est devenu particulièrement sensible à la «menace islamiste » à la suite des attentats terroristes perpétrés entre 2005 et $2007^{26}$, mais aussi à cause d'un sentiment de méfiance croissant envers l'immigration musulmane perçue comme une menace à l'identité et au mode de vie des Danois. La fameuse crise des caricatures de Mahomet, provoquée par la publication d'une série de cari-

26. Voir Kulish N., "New Terrorism Case Confirms That Denmark Is a Target », The New York Times, le 17 septembre 2007, http://www.nytimes.com/2007/09/17/world/ europe/17denmark.html?_r=0 (consulté le 26 mai 2014) 
catures éditoriales peu flatteuses du prophète dans le journal conservateur Jyllands-Posten en septembre 2005, n'a fait qu'aggraver les relations déjà difficiles entre Musulmans et non-Musulmans au Danemark ${ }^{27}$. La montée du sentiment antimusulman a renforcé les appuis au Parti populaire danois (Dansk Folkeparti), fondé en 1995 et dont le programme avait proclamé en 2002 que le Danemark «n'est pas un pays d'immigration et ne l'a jamais été. Ainsi, nous n'accepterons pas de nous transformer en société multi-ethnique 28 ». Ce parti devint rapidement la troisième formation politique au Parlement danois, et donc un acteur politique majeur dans un pays habituellement dirigé par des gouvernements de coalition. Au moment de la sortie de The Killing II, le Parti populaire constituait un soutien parlementaire indispensable à la coalition minoritaire de centre-droit formée par le Parti libéral et le Parti conservateur. Deuxièmement, suite à la publication d'un rapport interministériel sur l'état de la lutte contre le terrorisme au Danemark en 2005, le gouvernement a introduit une série de mesures pour renforcer la législation antiterroriste et augmenter les pouvoirs du service de sécurité et de renseignements danois (Politiets Efterretningstjeneste, PET) ${ }^{29}$.

Sur le plan intertextuel, The Killing II se situe d'abord dans la tradition des romans, films et séries télévisées policiers noirs scandinaves, tradition qui plonge ses racines dans les romans policiers socio-politiques des années 1960 et 1970 du célèbre couple suédois Maj Sjöwal and Per Wahlöö, et qui persiste aujourd'hui dans les romans du Suédois Henning Mankell, du Danois Jussi Adler-Olsen ou du Norvégien Jo Nesbø, et dans des séries télévisées comme Wallander (basée sur les romans de Mankell), Ørnen : En krimi odysée (Danemark, 2004-2006), Varg Veum (Norvège, 2007-2012) Arne Dabl (Suède, 2011-2012 et 2015) ou Bron/Broen (Suède-Danemark, 2011-2015) 30.

Les trois saisons de The Killing mettent aussi en vedette une policière peu orthodoxe, laquelle doit se frayer un chemin dans un monde masculin qui lui est souvent hostile. Elle rejoint ainsi des consœurs occupant des positions similaires dans d'autres pays et à d'autres époques, notamment la Britannique

27. Pour une analyse détaillée de cette affaire et ses conséquences, voir Hervik P., « The Danish Muhammad Cartoon Conflict », Current Themes in IMER Research, n 13, Malmö, 2012.

28. The Party Program of the Danish People's Party as Established in 2002, http://www.danskfolkeparti.dk/The_Party_Program_of_the_Danish_Peoples_Party (consulté le 18 mai 2015). Le PPD a récolté 26,7 \% des votes aux élections européennes de 2014, de loin le meilleur score des partis du pays. Danmarks Statistik, "EuropaParlamentsvalg søndag », 25 mai 2014 [Les élections au Parlement européen, dimanche 25 mai 2014], http://dst.dk/valg/Valg1475795/valgopg/valgopgHL.htm (consulté le 16 juillet, 2014).

29. Voir Politiets Efterretningstjeneste, " Anti-terrorism legislation ", https://www.pet.dk/English/Legal\%20matters/Anti\%20terrorism.aspx (consulté le 19 mai 2015) et Sullivan K., "Denmark Tries to Act Against Terrorism as Mood in Europe Shifts », The Washington Post, le 29 août 2005, http://www.washingtonpost.com/ wpdyn/content/article/2005/08/28/AR2005082800899.html (consulté le 26 mai 2014).

30. Sur la littérature et le cinéma policiers noirs scandinaves, voir Nestingen A, Crime and Fantasy in Scandinavia: Fiction, Film and Social Change, Seattle, University of Washington Press, 2008. 
Jane Tennison de la série Suspect numéro 1 (Prime Suspect) (1991-1996, 2003, 2006) et son homologue dans le remake américain de la même série, la Française Laure Berthaud (Engrenages) (cinq saisons entre 2005 et 2014), la Suédoise Saga Norén (Bron/Broen, 2011-2015) et ses homologues française et américaine dans les remakes de cette série, ainsi que l'Américaine Olivia Benson (New York, unité spéciale - Law and Order: Special Victims Unit, 1999).

En refusant d'accepter les versions officielles des événements, les deux protagonistes principaux de The Killing II, Lund et Buch, mènent eux-mêmes le processus de déconstruction/reconstruction des perceptions dominantes de la problématique sécuritaire du Danemark. Lund, en rejetant d'emblée la validité des indices qui pointent vers la culpabilité d'un militant islamiste, remet en question un élément-clé de l'imaginaire sécuritaire danois, la réalité de la «menace musulmane ». Et elle n'a pas peur de heurter de front le PET, qui traite la série d'assassinats dans le cadre de la lutte contre le terrorisme islamiste et tente, sans succès, d'écarter une policière qui ose mettre en doute sa définition de la menace.

Lund reste strictement à l'intérieur du cadre de l'enquête sur des crimes, et n'entre jamais dans leurs ramifications politiques ou sécuritaires (elle ne rencontre qu'une fois, et très brièvement, Buch au cours de la série). C'est au jeune ministre de la Justice de déconstruire le lien étroit entre crime, sécurité et politique. Lors de sa confrontation avec le Premier ministre, Buch apprend que celui-ci a toujours connu l'identité du meurtrier recherché par Lund et n'a rien dit parce qu'il s'agissait d'un membre des forces spéciales danoises, chargé d'une mission en Afghanistan menée sans l'autorisation du Parlement, comme l'exige la Constitution. La révélation de l'existence de cette mission aurait provoqué la chute du gouvernement. Aux objections de Buch, le Premier ministre offre une réponse désormais bien connue : « Nous sommes en guerre, comment aurions-nous pu faire autrement ? Parfois, il faut mettre la démocratie de côté pour se battre pour la démocratie. » Le prix à payer pour assurer la survie du gouvernement est de le rendre dépendant d'un parti d'extrême droite, qui cherche à durcir la législation antiterroriste, à mettre fin à l'immigration extra-européenne et à instaurer un état d'exception permanent, au nom de la défense des valeurs danoises.

Le développement d'internet, et surtout de sites de streaming comme Netflix et Amazon, au cours des dernières années, a considérablement renforcé la position dominante de la culture populaire visuelle comme première source de divertissement à travers le monde. L'accès à des films et à des séries télévisées n’a jamais été aussi facile. Pour cette seule raison, cette forme de culture populaire et les images du monde qu'elle projette fournissent déjà une matière première inestimable aux chercheurs en sciences sociales. Et cette 
matière première ne se trouve pas tant dans la "représentation », toujours aléatoire, de la réalité sociopolitique que proposent ces artefacts culturels que dans ce que ces derniers peuvent nous dire sur les sociétés dans lesquelles ils sont produits, souvent à l'insu de leurs créateurs.

La sécurité est un de ces thèmes qui s'imposent dans le cinéma et les séries télévisées depuis leur début, même quand, à première vue, il en semble totalement absent. Nous pensons, par exemple, à la question de l'identité nationale et au besoin constant de la définir et de la redéfinir, et que l'on retrouve en filigrane dans tant de films policiers, de drames sentimentaux ou de comédies produits à travers le monde. Presque tous les films tournés à Hollywood pendant la guerre froide évoquaient le National Security State. Dans ces conditions, les films et les séries présentent un terrain fertile pour les études critiques de sécurité.

Conscient du fait que les films et les programmes télévisés peuvent contribuer à faire avancer les études de sécurité sur plusieurs plans, par exemple sur celui de la théorie ${ }^{31}$, et qu'il existe plusieurs méthodes pour analyser les films et les programmes, nous avons opté pour un thème assez large, celui de la problématique sécuritaire de la société qui les a produits, et un mode d'analyse assez souple. Le recours à la notion de problématique sécuritaire, telle que nous l'avons définie, suppose une conception ouverte de ce qui compose le champ de la sécurité et qui caractérise les études critiques. Quant à la façon d'aborder les films et les séries d'une perspective critique, nous avons voulu proposer surtout un cadre d'analyse qui peut s'adapter à plusieurs approches théoriques, du marxisme au poststructuralisme. 